\title{
Promising Polyunsaturated Oils from Marine Haptophyta
}

\author{
Bakku RK ${ }^{1,2 *}$ \\ ${ }^{1}$ Faculty of Information, Systems and Engineering, University of Tsukuba, Japan \\ ${ }^{2}$ Tsukuba Life Science Innovation Program, University of Tsukuba, Japan
}

*Corresponding author: Ranjith Kumar Bakku, Faculty of Information, Systems and

Engineering, University of Tsukuba, 1-1-1 Tennodai, Tsukuba, Ibaraki 305-8573, Japan, Tel: +81-29-853-5449; Fax: +8129-853-5449; Email: bakku.kumar.kb@u.tsukuba.ac.jp

\section{Review article \\ Volume 2 Issue 5}

Received Date: September 21, 2018

Published Date: October 23, 2018

DOI: $10.23880 /$ jenr-16000143

\section{Abstract}

Energy and Environment play a key role for the sustainability and survival of a society. At present these are the two major concerns in current world. Rapidly increasing energy demands and decreasing healthy environmental conditions pose a serious threat to future generations of humanity. The quest to find clues for prediction of future environment from past information and search for alternate energy sources has already begun. In this regard, the photosynthetic marine micro algae and the organic compounds produce by them are considered as the potential targets to address the environmental challenges. Poly-unsaturated long chain ketones (PULCAs) are such compounds produced by few species of marine Haptophyta. These compounds are identified to be unique lipids which are considered as potential biofuel precursors. The PULCAs are generally called as alkenones and are comprised of more than $40 \%$ of total lipid content in haptophyte species like E.huxley and Gephyrocapsa. Current paper provides a brief overview on these compounds.

Keywords: PULCAs; Haptophyta; Bio-fuel; Biomarkers; Alkenones

\section{Introduction}

Due to over use of natural oil reserves there is a significant increase in $\mathrm{CO}_{2}$ levels as well as simultaneous decrease in the climatic conditions and energy reserves. This situation is leading towards energy crisis and global warming. In order to prevent further damage, the scientific community is searching for alternate solutions from the photosynthetic organisms. Life on earth has proliferated from simple single celled microbes in oceans to multi-cellular complex beings on land, water and air. Out of which marine photosynthetic microbes lie in the primary line of evolution. Marine phytoplankton evolved through a various symbiotic processes to thrive in response to environmental conditions and contributed to global bio-geochemical cycles [1].

Till date a wide range of algal species were discovered and are used as standard models for several research purposes in food, fuel and pharma industries. Some of them are of significant importance to scientific community because of their unique biochemical mechanisms and carbon containing products [2-4]. Especially, certain lipids like fatty acids, sterols, alcohols, Oxylipins etc., produced by these photosynthetic marine microbes like Cyanobacteria and diatoms are very useful in geophysical, food, biofuel and pharma industries. Such lipid deposition from plants and algae in the layers of earth from the past million years triggered formation of 
crude oil reserves. However, these are being depleted rapidly. Currently there is a high demand to explore renewable and environment friendly energy sources to prevent increasing $\mathrm{CO}_{2}$ levels and global temperature. Therefore photosynthetic micro algal lipids are extensively studied for this purpose.

Alkenones are one such unique lipid molecules produced by marine haptophyta. These lipids are widely considered as potential subjects for addressing environmental challenges. The haptophytes that produce alkenones are widely distributed in the open oceans and are considered to be dominant species that can survive through diverse nutrient fluctuations [5-7]. These organisms have been thrived in earth's waters over a million years through adverse environmental conditions. These alkenone producing organisms played a key role in contributing to earth's early biosphere through oxygen production, carbon and sulfur cycling $[3,4,8]$. The alkenones, produced and deposited into sea sediments, by these organisms are also identified to have significant paleo-climate information [5]. In addition, they are also assumed to be potential biofuel precursors. Various studies on alkenones have been carried out till date to elucidate their applications. This article is aimed to give a brief over view on the alkenone research with regard to their biological role and biofuel potential.

\section{Poly-Unsaturated Long Chain Ketones (Pulcas)}

Alkenones are unique neutral lipid molecules first discovered in the marine sediments $[9,10]$. The characteristic features of these unique lipids are very long carbon chains $\left(\mathrm{C}_{36}-\mathrm{C}_{40}\right), \sim(2$ to 4$)$-trans double bonds and a methyl or ethyl ketone functional group at one end as shown in figure $1[10,11]$. Alkenones along with other related compounds like alkenes and alkenoates are collectively referred to as polyunsaturated long chain alkenones (PULCAs). Only few marine haptophytes namely Emiliania, Gephyrocapsa, Isochrysis, Tisochrysis and Chrysotila are known to produce these components $[5,6,12]$.

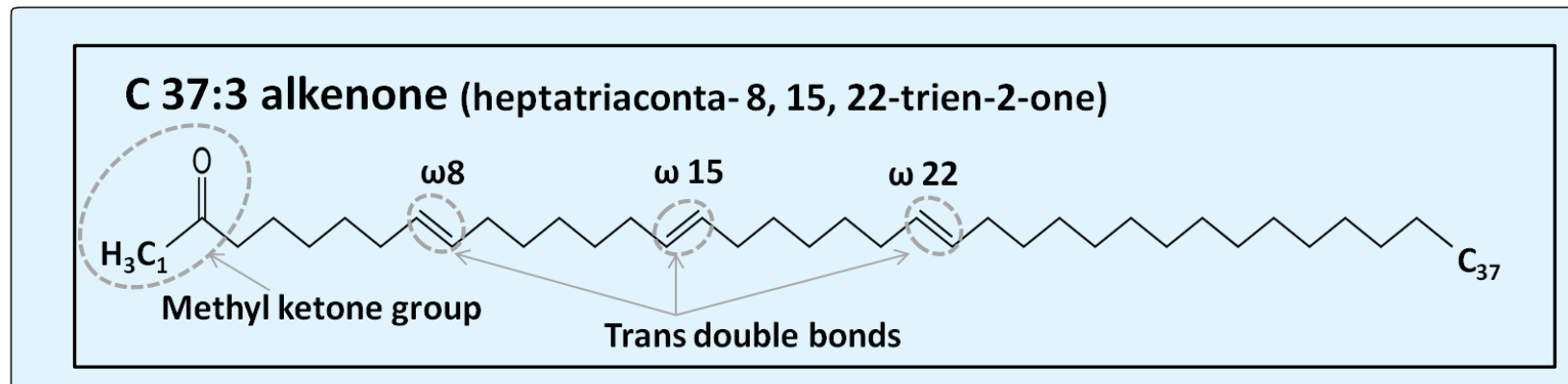

Figure 1: Figure showing structure of $\mathrm{C}_{37: 3}$ alkenone with its trans-double bonds and a methyl ketone group.

The alkenone composition, distribution and double bond number varies depending on algal species, habitat and the growth conditions like temperature, salinity and nutrient availability. For example, alkenones with two to three double bonds and $\mathrm{C}_{37}-\mathrm{C}_{39}$ carbon chain length are most commonly identified in Emiliania and Gephyrocapsa thriving in marine and lacustrine environments [5,9-15].

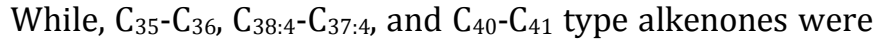
also produced by these haptophytes and specifically identified in sediments of black sea, cold waters, sulfaterich lakes and hyper-saline environments [16-20]. The trans-unsaturation of these molecules is identified to be linearly proportional to temperatures and therefore they are used as proxies to estimate ancient sea surface temperatures, SST [21-23]. These compounds are mainly useful in geophysical studies to estimate paleo temperatures and paleo $\mathrm{CO}_{2}$ [24-26]. Because of such wide distribution, unique structural features and applications, alkenones are considered useful macromolecular components in haptophytes.

Besides being widely accepted as biomarkers for temperature and $\mathrm{CO}_{2}$, alkenones are also assumed to be potential biofuel precursors. Several studies on the characteristics of alkenones speculated their biological role as neutral lipids, buoyancy regulators or structural backbones [10,27-31]. Their role as storage lipids like triacylglycerol (TAG) is highly under debate and yet to be explored. It was also observed that, TAGs are comparably produced in very low amounts compared to alkenones in haptophytes like E.huxleyi and Gephyrocapsa [6,32-34]. Alkenone unsaturation being temperature dependent and their role as storage lipids was speculated to have evolved through natural selection [30]. Furthermore, the 
mechanisms involved in their biosynthesis, trans unsaturation were also explored and identified to be downstream of fatty acid biosynthesis and elongation pathways [36-39]. In the process of unraveling their biosynthesis mechanisms, identification of the localization of alkenones was also studied. The abundance of alkenone composition from membrane fractions was found in endoplasmic reticulum and coccolith producing compartments, while fluroscence and nutrient/light stress studies showed present of nutral lipids in chloroplasts and lipid vesicles [40-41]. Despite such extensive studies on characteristics and applications of alkenones, their biological role and complete mechanism of synthesis are still unknown.

Among all alkenone producing haptophytes, E.huxleyi is the major producer of alkenones and a dominant marine coccolithophore [9,10,33,42]. Most studies are carried mainly using E.huxleyi. Studies on carbon flow in alkenone producing haptophytes showed that $15-20 \%$ of the carbon is incorporated in to lipids among which 63$75 \%$ is in the form of neutral lipids [27]. The carbon content is around 48-64\% under nutrient replete conditions/ normal conditions and tends to increase under nitrate or phosphate limitations [29,30,41,43]. Recently, nitrate limited experiments of Bakku et al. 2017 [44] also showed alkenones as major C storage pools under $\mathrm{N}$ - limitation in E. huxleyi as a significant increase in \%organic carbon $(15 \%$ Ca. to $27 \%$ Ca.) was observed upon transferring the cells from $\mathrm{N}$-replete to $\mathrm{N}$-limited conditions.

Initial studies on lipid class composition of 8 isolates of E. huxleyi showed that neutral lipid composition can vary from $38.3 \%$ to $67.3 \%$ of total lipid content during log to stationary phases [33]. Alkenones in some strains of E.huxleyi and Gephyrocapsa are known to occupy nearly $50-60 \%$ of the total lipid content and can increase upto $73-77 \%$ under stressed conditions [33,44,45]. In Isochrysis $s p$. though comparatively less, nearly $14 \% \mathrm{w} / \mathrm{w}$ of biodiesel are found to be alkenones [46]. Additional studies on lipid bodies of haptophytes like Tisochrysis lutea indicated that nearly $70-74 \%$ of its lipid body is also composed of alkenones [42]. Furthermore it was observed that using techniques like pyrolysis or butenolysis alkenone can be converted into short chain hydrocarbons like n-alkanes and jet-fuels [48-50]. Also, alkenones are considered to be stable molecules against photo oxidation due to embedded trans double bond geometry [36]. Having less unsaturation number, resistant to photo oxidation and absence of glycerol backbone are the advantages of these molecules over TAGs. However, alkenones cannot be used as a direct biofuels due their high boiling points $\left(>60^{\circ} \mathrm{C}\right)$ compared to TAGS [46,50,51]. Therefore, though the use of alkenones as biofuels could be advantageous technical difficulties in conversion of alkenoenes into industry level biofuels still persist. Identification of alkenone biosynthesis pathways and subsequent regulation towards production of short chain hydrocarbons could be an alternative way for efficient biofuel synthesis.

\section{Conclusion}

Renewable organic compounds that can serve as multipurpose resources are very useful for research and industry. Especially lipids that can serve as both biomarkers and biofuel molecules are rare and valuable sources for environmental studies. The PULCAs like Alkenones fit in this category perfectly. Alkenones are already well known for their applications in paleothermometry and paleo- $\mathrm{CO}_{2}$ analysis. On the other hand their potential to be used as biofuels is yet to be explored fully. At the moment though their biosynthesis mechanism is not known, their role as major storage lipids is confirmed. Despite their high melting points, their accumulation in haptophyte strains like E.huxleyi is very convincing for modeling towards large scale production. Future research on revealing alkenone biosynthesis pathways could help in directing towards synthesis of jet-fuel range hydrocarbons. In addition, cultivation of such haptophytes in open oceans could be the next step towards biofuel production.

\section{References}

1. Falkowski PG (1994) The role of phytoplankton photosynthesis in global biogeochemical cycles. Photosynthesis Res 39(3): 235-258.

2. Lloyd NDH, Canvin DT, Culver DA (1977) Photosynthesis and Photorespiration in Algae. Plant Physiol 59(5): 936-940.

3. Blankenship RE, Hartman H (1998) The origin and evolution of oxygenic photosynthesis. Trends Biochem Sci 23(3): 94-97.

4. Bendall DS, Howe CJ, Nisbet EG, Nisbet RER (2008) Introduction. Photosynthetic and atmospheric evolution. Philos Trans R Soc B Biol Sci 363(1504): 2625-2628.

5. Conte MH, Volkman JK, Eglinton G (1994) Lipid biomarkers of the Haptophyta. In: Green JC, 
Leadbeater BSC (Eds.), The Haptophyte Algae, Clarendon Press, pp: 351-77.

6. Volkman JK, Barrett SM, Blackburn SI, Sikes EL (1995) Alkenones in Gephyrocapsa oceanica: implications for studies of paleoclimate. Geochim Cosmochim Ac 59(3): 513-520.

7. Read BA, Kegel J, Klute MJ, Kuo A, Lefebvre SC, et al. (2013) Pan genome of the phytoplankton Emiliania underpins its global distribution. Nature 499(7457): 209-213.

8. Holligan PM, Fernandez E, Aiken J, Balch WM, Boyd P, et al. (1993) A biogeochemical study of the coccolithophore, Emiliania huxleyi, in the NorthAtlantic. Global Biogeochem Cycles 7(4): 879-900.

9. Volkman JK, Eglinton G, Corner EDS, Forsserg TEV (1980a) Long-chain alkenes and alkenones in the marine coccolithophorid Emiliania huxleyi. Phytochem 19(12): 2619-2622.

10. Volkman JK, Eglinton G, Corner EDS, Sargent JR (1980b) Novel unsaturated straight-chain $\mathrm{C}_{37^{-}}$ $\mathrm{C}_{39}$ methyl and ethyl ketones in marine sediments and a coccolithophore Emiliania huxleyi. Phys Chem Earth 12: 219-227.

11. Marlowe IT, Brassell SC, Eglinton G, Green JC (1984) Long chain unsaturated ketones and esters in living algae and marine sediments. Org Geochem 6: 135-141.

12. Theroux S, D'Andrea WJ, Toney J, Amaral-Zettler L, Huang YS (2010) Phylogenetic diversity and evolutionary relatedness of alkenone-producing haptophyte algae in lakes: Implications for continental paleotemperature reconstructions. Earth Planet Sci Lett 300(3-4): 311-320.

13. Conte MH, Thompson A, Eglinton G (1995) Lipid biomarker diversity in the coccolithophorid Emiliania huxleyi (Prymnesiophyceae) and related species Gephyrocapsa oceanica. J Phycol 31(2): 272-282.

14. Cranwell PA (1985) Long-chain unsaturated ketones in recent lacustrine sediments. Geochim Cosmochim Ac 49(7): 1545-1551.

15. Sawada K, Handa N, Shiraiwa Y, Danbara A, Montani S (1996) Long-chain alkenones and alkyl alkenoates in the coastal and pelagic sediments of the northwest North Pacific, with special reference to the reconstruction of Emiliania huxleyi and Gephyrocapsa oceanica ratios. Org Geochem 24(8-9): 751-764.

16. Theissen KM, Zinniker DA, Moldowan JM, Dunbar RB, Rowe HD (2005) Pronounced occurrence of longchain alkenones and dinosterol in a 25,000-year lipid molecular fossil record from Lake Titicaca, South America. Geochim Cosmochim Ac 69(3): 623-636.

17. Toney JL, Huang Y, Fritz SC, Baker PA, Grimm E, et al. (2010) Climatic and environmental controls on the occurrence and distributions of long chain alkenones in lakes of the interior United States. Geochim Cosmochim Ac 74(5): 1563-1578.

18. Xu L, Reddy CM, Farrington JW, Frysinger GS, Gaines $\mathrm{RB}$, et al. (2001) Identification of a novel alkenone in Black Sea sediments. Org Geochem 32(5): 633-645.

19. Rontani JF, Beker B, Volkman JK (2004) Long-chain alkenones and related compounds in the benthic haptophyte Chrysotila lamellosa Anand HAP 17. Phytochem 65(1): 117-126

20. Zhao J, An C, Longo WM, Dillon JT, Zhao Y, et al. (2014) Occurrence of extended chain length C41 and C42 alkenones in hypersaline lakes. Org Geochem 75: 48-53.

21. Brassell SC, Eglinton G, Marlowe IT, Pflaumann U, Sarnthein M (1986) Molecular stratigraphy: a new tool for climatic assessment. Nature 320: 129-133.

22. Prahl FG, Wakeham SG (1987) Calibration of unsaturation patterns in long-chain ketone compositions for palaeotemperature assessment. Nature 330: 367-369.

23. Eglinton G, Bradshaw SA, Rosell A, Sarnthein M, Pflaumann U, et al. (1992) Molecular record of secular sea surface temperature changes on 100 year time-scales for glacial terminations I, II and IV. Nature 356: 423-426.

24. Jasper JP, Hayes JM (1990) A carbon isotope record of $\mathrm{CO}_{2}$ levels during the late Quaternary. Nature 347: 462-464.

25. Freeman KH, Pagani M (2005) Alkenone-Based Estimates of Past CO2 Levels: A Consideration of Their Utility Based on an Analysis of Uncertainties. In: Baldwin I, (Eds.), A History of Atmospheric $\mathrm{CO}_{2}$ and Its Effects on Plants, Animals, and Ecosystems. 
Ecological Studies (Analysis and Synthesis), Springer, New York, NY, 177.

26. Pagani M, Freeman KH, Ohkouchi N, Caldeira K (2002) Comparison of water column $\left[\mathrm{CO}_{2}\right.$ aq] with sedimentary alkenone-based estimates: a test of the alkenone- $\mathrm{CO}_{2}$ proxy. Paleoceanography 17(4): 12-121-12.

27. Fernández E, Balch WM, Marañón E, Holligan PM (1994) High rates of lipid biosynthesis in cultured, mesocosm and coastal populations of the coccolithophore Emiliania huxleyi. Mar Ecol Prog Ser 114: 13-22.

28. Fernández E, Marañon E, Balch WM (1996a) Intracellular carbon partitioning in the coccolithophorid Emiliania huxleyi. J Mar Syst 9(1-2): 57-66.

29. Bell MV, Pond D (1996b) Lipid composition during growth of motile and coccolith forms of Emiliania huxleyi. Phytochemistry 41(2): 465-471.

30. Epstein BL, D'Hondt S, Hargraves PE (2001) The possible metabolic role of C37 alkenones in Emiliania huxleyi. Org Geochem 32(6): 867-875.

31. Sawada K, Shiraiwa Y (2004) Alkenone and alkenoic acid compositions of the membrane fractions of Emiliania huxleyi. Phytochemistry 65(9): 1299-1307.

32. Volkman JK (1986) A review of sterol markers for marine and terrigenous organic matter. J Org Geochem 9(2): 83-99.

33. Pond DW, Harris RP (1996) The lipid composition of the coccolithophore Emiliania huxleyi and its possible ecophysiological significance. J Mar Biol Assoc UK 76(3): 579-594.

34. Malitsky S, Ziv C, Rosenwasser S, Zheng S, Schatz D, et al. (2016) Viral infection of the marine alga Emiliania huxleyi triggers lipidome remodeling and induces the production of highly saturated triacylglycerol. New Phytol 210(1): 88-96.

35. Shiraiwa Y, Kubota M, Sorrosa JM, Wettstein-Knowles P (2005) Alkenone synthesis in Emiliania huxleyi probed with radiolabeled substrate and a fatty acid synthesis inhibitor. In: Saxena N (Eds.), Recent Advances in Marine Science and Technology, PACON International, Hawaii, pp: 27-36.
36. Rontani JF, Prahl FG, Volkman JK (2006a) Characterization of unusual alkenones and alkyl alkenoates by electron ionization gas chromatography mass spectrometry. Rapid Commun Mass Spectrom 20(4): 583-588.

37. Rontani JF, Prahl FG, Volkman JK (2006b) Reexamination of the double bond positions in alkenones and derivatives: Biosynthetic implications. J Phycol 42(4): 800-813.

38. Zheng Y, Dillon JT, Zhang Y, Huang Y (2016) Discovery of alkenones with variable methyleneinterrupted double bonds: implications for the biosynthetic pathway. J Phycol 52(6): 1037-1050.

39. Kitamura E, Kotajima T, Sawada K, Suzuki I, Shiraiwa Y (2018) Cold-induced metabolic conversion of haptophyte di-to tri-unsaturated C37alkenones used as palaeothermometer molecules. Sci Rep 8(1): 1-11.

40. Sawada K, Shiraiwa Y (2004) Alkenone and alkenoic acid compositions of the membrane fractions of Emiliania huxleyi. Phytochemistry 65(9): 1299-1307.

41. Eltgroth ML, Watwood RL, Wolfe GV (2005) Production and cellular localization of neutral longchain lipids in the haptophyte algae Isochrysis galbana and Emiliania huxleyi. J Phycol 41(5): 10001009.

42. Okada H, Honjo S (1973) The distribution of oceanic coccolithophores in the \{P\}acific. Deep Sea Res 20(4): 355-374.

43. Prahl FG, Sparrow MA, Wolfe GV (2003) Physiological impacts on alkenone paleothermometry. Paleoceanography 18(2).

44. Bakku RK, Araie H, Hanawa Y, Yoshihiro S, Iwane S (2018) Changes in the accumulation of alkenones and lipids under nitrogen limitation and its relation to other energy storage metabolites in the haptophyte alga Emiliania huxleyi CCMP 2090. J Appl Phycol 30(1): 23-36.

45. Pan H, Culp RA, Sun MY (2017) Influence of physiological states of Emiliania huxleyi cells on their lipids and associated molecular isotopic compositions during microbial degradation. J Exp Mar Bio Ecol 488: 1-9.

46. Oneil GW, Carmichael CA, Goepfert TJ, James MF, Gerhard K (2012) Beyond fatty acid methyl esters: 


\section{Journal of Ecology \& Natural Resources}

Expanding the renewable carbon profile with alkenones from Isochrysis sp. Energy and Fuels 26(4): 2434-2441.

47. Shi Q Araie H, Bakku RK, Fukao Y, Rakwal R, et al. (2015) Proteomic analysis of lipid body from the alkenone-producing marine haptophyte alga Tisochrysis lutea. Proteomics 15(23-24): 4145-4158.

48. Wu Q, Shiraiwa Y, Takeda H, Guoying S, Jiamo F (1999) Liquid-saturated hydrocarbons resulting from pyrolysis of the marine coccolithophores Emiliania huxleyi and Gephyrocapsa oceanica. Mar Biotechnol 1(4): 346-352.

49. Wu Q, Shiraiwa Y, Takeda H, Sheng G, Fu J (1999b) Liquid-saturated hydrocarbons resulting from pyrolysis of the marine coccolithophores Emiliania huxleyi and Gephyrocapsa oceanica. Mar Biotechnol 1(4): 346-352.

50. Oneil GW, Culler AR, Williams JR, Noah PB, Garrett JG, et al. (2015) Production of jet fuel range hydrocarbons as a coproduct of algal biodiesel by butenolysis of long-chain alkenones. Energy Fuels 29(2): 922-930.

51. Oneil GW, Williams J, Wilson-Peltier J, Gerhard K, Christopher MR, et al. (2016) Experimental Protocol for Biodiesel Production with Isolation of Alkenones as Coproducts from Commercial Isochrysis Algal Biomass. J Vis Exp 24(113): 1-7. 